\title{
Miradas sobre la mendicidad infantil en la ciudad de Córdoba en las primeras décadas del siglo XX
}

\author{
Outlooks on Child Mendicity \\ in the City of Córdoba (Argentina) in the First Decades of \\ the 20th Century
}

\author{
Fernando J. Remedi \\ Instituto de Estudios Históricos, \\ Centro de Estudios Históricos "Prof. Carlos S. A. Segreti", \\ Consejo Nacional de Investigaciones Científicas y Técnicas, \\ Universidad Nacional de Córdoba (Argentina) \\ fremedi@yahoo.com.ar / fjremedi@gmail.com
}

\begin{abstract}
Resumen
Este trabajo participa de una línea de investigación dedicada al estudio del mundo de los pobres en la ciudad de Córdoba (Argentina) entre 1870 y 1930, que pretende reconstruir cómo ellos experimentaron las grandes transformaciones de esa época, en especial el intenso proceso de modernización, la veloz urbanización, la creciente institucionalización estatal y el sostenido crecimiento económico. En ese marco, este trabajo tiene como objetivo avanzar en la reconstrucción de las miradas, y de las concepciones subyacentes a ellas, de los mendigos y la mendicidad que circulaban en Córdoba entre fines del siglo XIX y el primer tercio del XX, poniendo énfasis en las vehiculizadas a través de la prensa local. En concreto, la atención se focaliza sobre la mendicidad infantil en la ciudad de Córdoba en las décadas de 1910 y 1920, un período en que dicho fenómeno recién parece adquirir entidad como problemática social en dicha ciudad.
\end{abstract}

Palabras Clave

Pobres; Mendicidad; Mendigos; Niñez; Beneficencia; Asistencia Social.

\begin{abstract}
This work is part of a line of research dedicated to the study of the world of the poor in the city of Córdoba (Argentina) between 1870 and 1930. It seeks to reconstruct the way the poor experienced the big transformations of the time, specially the intense process of modernization, the rapid urbanization, the growing state institutionalization and the sustained economic growth. Within that framework, the goal of this investigation is to advance in the reconstruction of the outlooks on mendicity and beggars, and the underlying beliefs of such outlooks, which were present in Córdoba between the end of the $19^{\text {th }}$ Century and the first third of the $20^{\text {th }}$, with an emphasis on those expressed through the local press.

Esta obra está sujeta a la Licencia Reconocimiento-NoComercial-CompartirIgual 4.0 Internacional de Creative Commons. http://creativecommons.org/licenses/by-nc-sa/4.0/

(cc) BY-NC-SA
\end{abstract}




\section{Miradas sobre la mendicidad infantil en la ciudad de Córdoba en las primeras décadas del siglo $\mathrm{XX}$}

In particular, attention is focused on child mendicity in the city of Córdoba in the 1910s and 1920 s, a period in which such phenomenon seems to start gaining significance as a social problem in said city.

\section{Keywords}

Poor; Mendicity; Beggars; Childhood; Charity; Social Care.

\section{Introducción}

Este trabajo se inserta dentro de una línea de indagación mayor interesada por el mundo de los pobres en la ciudad de Córdoba entre el último tercio del siglo XIX y el primero del XX. Su objetivo general es reconstruir las experiencias de los pobres de grandes transformaciones de esa época como el intenso proceso de modernización, la veloz urbanización, la creciente institucionalización estatal y el sostenido crecimiento económico, así como su obrar en el marco de ellas.

Teniendo presente que la pobreza, además de una realidad económica era "una imagen social que se percibía como tal" (Woolf, 1990, p. 95), este trabajo tiene como objetivo avanzar en la reconstrucción de las miradas, y las concepciones subyacentes a ellas, de los mendigos y la mendicidad que circulaban en Córdoba en el giro del siglo XIX al XX, poniendo énfasis en las vehiculizadas a través de la prensa local. ${ }^{1}$ La atención se focaliza sobre la mendicidad infantil en dicha ciudad en las décadas de 1910 y 1920, período en que dicho fenómeno recién parece adquirir entidad como problemática social en ese espacio. Por otra parte, en coincidencia con los primeros signos locales de la crisis económica prebélica, en 1913 en la ciudad se aprobó una ordenanza sobre represión de la mendicidad en lugares públicos, iniciativa que había quedado "olvidada" en el Concejo Deliberante desde 1910. El período se extiende hasta 1930 , cuando se sienten localmente las secuelas de la crisis económica internacional.

La mendicidad despertó la atención de historiadores de otras latitudes, a menudo como parte de un universo mayor que la incluía como el pauperismo, los pobres y el mundo de la pobreza. Como señalaba hace algo más de 25 años Carasa Soto (1992),

\footnotetext{
${ }^{1}$ Se recurrió a tres periódicos de la ciudad: Los Principios y La Voz del Interior -los de mayor tiraday El País. Los Principios comenzó a editarse en 1894, bajo la dirección de Monseñor Juan Martín Yáñiz y Paz, con una tirada de 500 ejemplares; en esa época llevaba bajo su título la leyenda "Órgano de la Asociación Juventud Católica", que hacia los últimos años de la década de 1910 fue sustituida por "Diario Independiente, decano de la prensa de Córdoba". Tenía una tendencia decididamente católica y de claro tono conservador, fortalecido para fines de los años 1910. La Voz del Interior fue fundado en 1904 por Silvestre Remonda y Juan Naso, con una tirada de 300 ejemplares. Reflejaba las tendencias de la fracción más progresista del radicalismo local, de una ideología más bien liberal y anticlerical. El País, de aparición diaria, fundado en 1926, durante la gobernación de Ramón J. Cárcano, era editado por la Sociedad Anónima El País, presidida por Miguel Ángel Cárcano -hijo del mandatario aludido- y entre sus autoridades estaban Emilio F. Olmos -a la sazón intendente de Córdoba-, Alejandro Centeno, Francisco Espinosa Amespil, Martín Gil, Manuel J. Astrada, Carlos Astrada Ponce, Carlos E. Deheza, D. Granillo Barros. El periódico reflejaba las ideas de un sector prestigiado y de fuerte gravitación de las fuerzas conservadoras locales expresadas en el Partido Demócrata.
} 


\section{Fernando J. Remedi}

un referente de la historiografía española sobre el pauperismo, uno de los tantos retos de ese campo era avanzar sobre las representaciones de la pobreza en la ideología asistente, las iconográficas, las literarias y las de la prensa. En esta línea, algunos de los avances historiográficos concretados en España referidos a la segunda mitad del siglo XIX e inicios del XX resultaron inspiradores para esta contribución, al concentrarse sobre cómo la prensa reflejaba la mendicidad y las soluciones que proponía para acabar con ella (Rodríguez Martín, 2017; Velasco Mesa, 1995). A esto cabe añadir, para América Latina, los estudios de Lorenzo (2015, 2018) sobre la mendicidad en la ciudad de México entre las últimas décadas del siglo XIX y el primer tercio del XX. En cambio, la mendicidad despertó muy poco la atención de los historiadores en la Argentina, como lo demuestra su exigua producción sobre ella para el período de nuestro interés. ${ }^{2}$ En algunos casos, dicha cuestión aparece marginalmente o, mejor aún, diluida dentro de trabajos que focalizan sobre otras problemáticas y desde otras perspectivas analíticas o campos de estudio, especialmente la historia de la infancia, no así la de los pobres y la pobreza (Aversa, 2003; Freidenraij, 2016; Paz Trueba, 2012, 2015, 2018; Zapiola, 2009, 2010, 2018).

Pese a la escasez de indagaciones específicas, la mendicidad fue una dimensión social más, entre otras, que acompañó a los procesos de progreso productivo, modernización, crecimiento demográfico y urbano que experimentó la Argentina, y Córdoba en particular, entre el último tercio del siglo XIX y el primero del XX. En nuestra investigación más amplia sobre la temática se postula que la intensa sensibilidad social que visualizamos por la mendicidad en la Córdoba de entre siglos obedeció a dos fenómenos. Por un lado, al incremento real del número de personas que -de manera regular u ocasional- ejercían esa actividad. Por otro, a que el aumento generalizado -pero no equitativo- del bienestar, provocado por el crecimiento económico y la modernización urbana, ponía más en evidencia, por contraste, las carencias de los sectores menos favorecidos. En otras palabras, la expansión económica impulsó el bienestar y, simultáneamente, la desigualdad social, agudizando la percepción de la pobreza y, como parte integrante y evidente de ella, de la mendicidad.

Por otra parte, el interés por la indagación de las miradas y las concepciones acerca de la mendicidad deriva de la convicción de que ellas no son parte de una superestructura mental o cultural que flota sobre la realidad material y social, sino que ambas están arraigadas en y en interacción con estas últimas. ${ }^{3}$ Miradas y concepciones tenían consecuencias prácticas, corporizadas en el diseño y la operatividad de dispositivos de intervención social sobre la mendicidad y los mendigos, cuya investigación se reserva para el futuro. Los distintos discursos -bajo

\footnotetext{
2 Moreno (2012) es el único trabajo sobre mendicidad para la Argentina del período (en términos estrictos es un poco anterior).

3 En otro sitio (Remedi, 2011, pp. 17-19) profundizamos en la complejidad de la relación entre representaciones y realidades materiales y sociales, en tono de crítica a los reduccionismos culturalistas de alguna historiografía de las últimas décadas.
} 


\section{Miradas sobre la mendicidad infantil en la ciudad de Córdoba en las primeras décadas del siglo XX}

diversas modalidades- acerca de la pobreza, a veces -como destaca Rheinheimer (2009)- se alejaron mucho de la vida real en la necesidad, pero no por ello la determinaron menos, a través de la concesión o no de ayuda, las discriminaciones, las persecuciones o los programas educativos (p. XII).

En el pasado existieron diversos mundos vitales dentro de la pobreza en los cuales transcurrió la existencia de los pobres, con diferencias y elementos en común (Rheinheimer, 2009, p. XIV). Desde la perspectiva analítica ya enunciada, aquí se focaliza sobre un pequeño fragmento diferenciado dentro de ese universo amplio, dinámico y complejo, compuesto por los niños que mendigaban. ${ }^{4}$

\section{Persistencia y masividad de la mendicidad urbana}

Una ojeada a las páginas de la prensa de Córdoba del último tercio del siglo XIX y primeros decenios del XX deja la sensación de una presencia abundante y persistente de mendigos en la ciudad. Llama la atención la masividad atribuida a la mendicidad y, atentos al discurso de la prensa, su crecimiento a lo largo del período. Son tópicos recurrentes aquellos que aluden a la mendicidad en términos de "asombroso desarrollo", "incremento alarmante", "calles sembradas de mendigos", y sobre ellos se subraya su "cantidad inmensa", "infinidad", "tan considerable número". La mendicidad se constituyó como problema social en la Córdoba del viraje de siglo, inscripto entre las preocupaciones de las elites dirigentes, las autoridades policiales y municipales, la prensa y sectores integrantes de aquellas que conformaban organizaciones benéficas. La mendicidad como problema social presentaba facetas morales, urbanísticas, higiénicas, sanitarias, estéticas, entre otras. $^{5}$

La mendicidad tenía consecuencias morales y sociales indeseables y alarmantes, porque se consideraba que estaba en el origen del vicio, la pérdida de la dignidad, la corrupción de las costumbres, la iniciación en el delito. Individuos que, o bien de inicio hacían de la mendicidad una estrategia de supervivencia para sortear una mala coyuntura, o bien la practicaban como un acto de picardía, comenzaban a transitar un camino que -se concebía- los conducía hacia la degradación moral.

Por sus connotaciones morales y sus consecuencias de esta naturaleza sobre el conjunto social, con mucha frecuencia la mendicidad aparece metafóricamente asociada a una enfermedad degenerativa que afectaba al cuerpo social y amenazaba su desenvolvimiento. Estas metáforas organicistas son recurrentes y parecen emerger casi "naturalmente" en los discursos de la prensa cuando se alude a la

\footnotetext{
${ }^{4}$ Del mismo modo, Lorenzo (2015) distingue analíticamente y construye como objeto de estudio a los mendigos como grupo diferenciado entre los pobres de la ciudad de México en el cambio del siglo XIX al XX, por sus condiciones de vida y relaciones con la asistencia a través de las formas de atención a ellos, distinguibles de las destinadas a otros grupos (vagos, viudas, huérfanos, delincuentes) (pp. $343,347)$.

${ }^{5}$ Remedi (2017, pp. 518-528) para un examen detallado de cada una de ellas.
} 


\section{Fernando J. Remedi}

mendicidad o los mendigos en términos de "enfermedad social", "peste", "plaga social”, "lepra social”, "cáncer social”, a menudo asociadas a un carácter infeccioso muy agresivo, con riesgos de propagación, que llegaba a amenazar a la totalidad de la vida social. ${ }^{6}$

El desaseo corporal y de las ropas, la exhibición de mutilaciones e incapacidades físicas y la exposición de síntomas de enfermedades eran algo más que un problema (real o supuesto) higiénico o sanitario. Era una corporalidad que provocaba incomodidad, desagrado, repulsión, asco, afectaba la sensibilidad emocional y sobre todo estética de los habitantes de la ciudad, o por lo menos de sus sectores acomodados. La prensa se hacía eco de ese malestar social, como ocurría a fines de los años 1920 cuando se denunciaba cómo el ocio disfrutado al aire libre por el trabajador los domingos era interrumpido y perjudicado por la irrupción repentina del mendigo y su solicitud de limosna, que terminaban "manchándole la alegría con su miseria física, alegría que acaso sea la única después de toda una semana de pesada labor, y que el pordiosero se la amarga". ${ }^{7}$ En los inicios de ese decenio, la prensa reclamaba por la reclusión en un asilo, hospital o lazareto de aquellos individuos que, incapacitados para el trabajo y con visibles deformidades o mutilaciones, se dedicaban a la mendicidad, para protegerlos y, a la vez, evitar "la mala impresión (...) en la vía pública". ${ }^{8}$ Los mendigos y su estética afeaban la ciudad, producían malestar en sus habitantes, representaban una mácula para la modernización urbana y social en marcha desde el último tercio del siglo XIX. La prensa reiteraba hasta el cansancio las mismas fórmulas para caracterizarla: "mala impresión", "cuadros desagradables y repugnantes", espectáculo "desagradable", "triste y depresivo", "poco amable", "vergonzoso". 9

Desde el mismo punto de vista, la mendicidad afectaba sensiblemente la imagen de modernidad que se esperaba que la ciudad proyectara, dejando una impresión por lo menos desagradable en los visitantes. Ésta remitía, no sólo a una percepción estética, sino que se proyectaba también sobre los comportamientos, las prácticas y las concepciones vigentes en la sociedad local. La proliferación de hombres, mujeres y menores que ejercían la mendicidad podía sembrar dudas en el visitante sobre el espíritu caritativo, la generosidad, la solidaridad, la sensibilidad social y el desenvolvimiento de las instituciones asistenciales en la ciudad. ${ }^{10}$ La afluencia de

\footnotetext{
${ }^{6}$ Los Principios (LP), Córdoba, 09/01/1898, p. 4, 27/04/1901, p. 1, 25/01/1905, p. 1, 21/01/1906, p. 2, 26/04/1907, p. 2, 11/01/1917, p. 1, 12/06/1918, p. 1, 22/10/1920, p. 1; La Voz del Interior (LVI), Córdoba, 23/07/1925, p. 12, 03/01/1928, p. 8, 15/03/1929, p. 16, 24/01/1930, p. 14; El País $(E P)$, Córdoba, 04/08/1930, p. 6.

${ }^{7} L P, 02 / 09 / 1928$ p. 7. Otros testimonios sobre la corporalidad de los mendigos y su impacto en la sensibilidad social: $L V I, 05 / 06 / 1920$, p. 4,08/06/1928, p. 13, 02/04/1930, p. 14.

${ }^{8} \mathrm{LP}, 11 / 03 / 1922$, p. 1.50 años antes, la prensa sostenía los mismos argumentos cuando abogaba por la construcción de un asilo de mendigos, enfatizando en su corporalidad y el rechazo y la repugnancia que provocaba por la exhibición de "granos asquerosos", rostros carcomidos, mutilaciones en la nariz, boca o cara, etc. El Eco de Córdoba, 24/03/1872, p. 3.

${ }_{9}$ Además de los ya aludidos: $L P, 27 / 02 / 1910$, p. 7,05/10/1928, p. 1 ; $L V I, 13 / 08 / 1922$, p. 6; EP, 31/12/1927, p. 8, 08/05/1928, p. 6, 01/01/1930, p. 7.

${ }^{10}$ En la ciudad española de Pontevedra parte de la prensa de fines del siglo XIX e inicios del XX consideraba que los mendigos daban "una imagen muy negativa de la cultura de la ciudad y de sus
} 


\section{Miradas sobre la mendicidad infantil en la ciudad de Córdoba en las primeras décadas del siglo XX}

mendigos en espacios como las puertas de restaurantes, cafés y salas de espectáculos, las estaciones de ferrocarril, entre otros, contribuían a difundir una mala (e indeseada) imagen de la sociedad cordobesa. Además, se sostenía que ella no se ajustaba a la realidad, porque se construía sólo sobre la base de apreciaciones $\mathrm{y}$ sugestiones superficiales y de momento, focalizadas en un fragmento sobreexpuesto- del tejido social. La presencia de mendigos podía ser leída como una evidencia de los límites de la modernización en curso, del progreso alcanzado por ella y por la sociedad que la habitaba. ${ }^{11}$

\section{Etiología de la mendicidad infantil en Córdoba}

En la Córdoba del giro del siglo XIX al XX la mendicidad era concebida como una cuestión de naturaleza personal y moral; la capacidad y la predisposición para el trabajo delineaban una frontera, en principio conceptualmente nítida, que distinguía entre mendigos auténticos -socialmente legitimados como tales, dignos de limosna y ayuda social- y vagos que se habían vuelto mendigos falsos, a los cuales cabía la marginación social y la exclusión del socorro material en caso de persistir en su pereza y falta de ética laboral (Remedi, 2017).

Sin embargo, pese a la persistente vigencia de esa concepción, en coincidencia con la Gran Guerra empezaron a emerger novedosas miradas, más matizadas y complejas, sobre la mendicidad y las razones de su existencia y desarrollo. Junto a las concepciones tradicionales, aún vigentes sobre las razones personales y morales de la mendicidad, que remitían a una responsabilidad individual, comenzaron a destacarse -aunque aún tímidamente- las causas socioeconómicas de ese fenómeno, una causalidad social, y por tanto, cierta responsabilidad colectiva en el mismo (Remedi, 2017). La capacidad y la voluntad de trabajar solían enfrentar la ausencia de oportunidades provocada por desfavorables circunstancias que, coyunturalmente, afectaban a la dinámica económica y al mercado laboral. En un período marcado por el crecimiento sostenido, entre el último tercio del siglo XIX y primeras décadas del XX, la desaceleración de su ritmo o la paralización productiva temporal condicionaban fuertemente -para muchos impedían- el acceso al mercado laboral y reducían a muchos trabajadores a la condición de mendigos, como ocurrió en la coyuntura económica creada por la Gran Guerra. En ésta convergieron una ralentización de la economía, la caída de los salarios reales, una notable y sostenida suba de los precios de los alimentos y una significativa desocupación (Remedi, 2003).

\footnotetext{
habitantes, que representaban un obstáculo a la modernidad y un germen de inmoralidad y, además, que resultaban poco decorativos" (Rodríguez Martín, 2017, p. 408).

${ }^{11}$ Algo semejante establece Velasco Mesa (1995) para Sevilla en el giro del siglo XIX al XX, quien sostiene -a partir del discurso de la prensa- que la mendicidad llegaba a "suponer un índice para medir y denunciar el «atraso» -léase la ausencia de progreso- de una comunidad o país" (p. 258).
} 


\section{Fernando J. Remedi}

En ese momento emerge de manera regular en la prensa local la mendicidad infantil como cuestión de interés social específico. Su emergencia y consolidación seguramente tenían relación directa con la creciente visibilización de la actividad mendicante de niños y menores por las calles, consecuencia de la persistencia e intensidad de la crisis económica inaugurada en 1913 y agudizada hacia fines de la guerra. En este contexto, la mendicidad infantil fue un recurso más, entre otros, de aquellos que conformaron las estrategias de supervivencia de los pobres en el marco de la crisis, sea que se solicitara limosna a título personal y por iniciativa del niño, sea que se lo hiciera a instancias de sus padres o algún tutor. En coincidencia con la profundización de la crisis, en 1917-18, la prensa no dejaba de reconocer -aunque a veces parecería que a regañadientes-, las razones más profundas y coyunturales de la expansión de la mendicidad infantil, atribuyéndolo al crecimiento de la pobreza. En un editorial del diario católico Los Principios, titulado "Un problema social”, sobre la práctica mendicante de los infantes se expresaba:

Las condiciones actuales de la vida, crean, según es de notoriedad, una situación angustiosa a numerosos hogares humildes, faltos de recursos para subvenir a las más apremiantes e ineludibles necesidades de su propia subsistencia. El extraordinario desarrollo de la desocupación obrera contribuye también a la agravación de ese estado de cosas. ${ }^{12}$

Desde otro punto de vista, la entidad e identidad propias de la mendicidad infantil, distinguiéndose de la adulta, es una cuestión que forma parte de un proceso sociohistórico mayor por el cual, desde fines del siglo XIX, se fue produciendo una delimitación del universo de los niños respecto del mundo de los adultos, diferenciándose entre aquello que se estimaba apropiado para los pequeños y aquello que no lo era. Como parte de esa delimitación creciente, la presencia y la circulación infantiles en el espacio público, el ejercicio de una libertad excesiva por parte de ellos en ese ámbito, las sociabilidades que al amparo de ésta los niños desarrollaban en plazas, veredas y mercados -entre otros sitios-, bajo una débil o ausente supervisión adulta, fueron concebidos como inapropiados, perjudiciales, negativizados, cargados de peligrosidad y asociados a la "mala vida" (Freidenraij, 2016, pp. 165-166, 193).13

Por otra parte, las miradas sobre la mendicidad infantil destacaban corporalidades algo distintas a las consideradas cuando se trataba de adultos en dicha actividad y, además, se movilizaban otras sensibilidades. Por lo común, se enfatizaba en una corporalidad debilitada, disminuida, subdesarrollada, y despertaba reacciones en

\footnotetext{
12 LP, 11/06/1918, p. 1.

13 Según la autora (2016), en la Buenos Aires de 1885-1920, esa diferenciación creciente entre el mundo adulto y el infantil supuso el corrimiento de los niños del espacio público, un apartamiento que no fue natural sino fruto de una intervención sistemática de la policía y una presión social no menos insidiosa sobre la inconveniencia de la presencia de aquellos en las calles (p. 166).
} 


\section{Miradas sobre la mendicidad infantil en la ciudad de Córdoba en las primeras décadas del siglo $\mathrm{XX}$}

términos de pena, compasión, conmiseración, en vez de las ya aludidas de repugnancia, repulsión y otras semejantes dirigidas hacia los mendigos adultos, aun cuando ambos grupos etarios compartían algunos rasgos tales como la pobreza y la escasez de vestimenta e higiene. ${ }^{14}$

Aunque el rigor de las circunstancias materiales imponía el reconocimiento de las razones profundas de la presencia y extensión de la mendicidad infantil, sin embargo, inmediatamente después se recurría, con mayor énfasis e insistencia, a argumentos que apuntaban a causas de otra naturaleza y que suponían una instrumentalización, juzgada ilegítima, de los niños por sus padres, madres o tutores. Todos ellos explotaban a los niños como limosneros, bajo diversas modalidades. ${ }^{15}$

En algunos casos, se trataba de la permanentemente cuestionada, desde antes del período considerado, figura del "lazarillo" acompañante de algún anciano, por lo común afectado de una afección y/o discapacidad, real o supuesta. Por lo general de esta forma aparecen inicialmente asociados los niños a la mendicidad en la prensa, antes del período, cuando aún se estimaba a ese fenómeno como algo poco difundido en el contexto local, como acontecía en 1906-07, a diferencia de lo ocurrido en Buenos Aires. ${ }^{16}$

Aunque sin desaparecer, esa figura y las críticas asociadas parecen perder mucha gravitación para las décadas de 1910 y 1920, desplazadas por otras modalidades de explotación de la mendicidad infantil a cargo de padres y madres que -bajo su supervisión- enviaban a sus hijos a limosnear, o los alquilaban a un tercero con el mismo fin, o los utilizaban como recurso histriónico en su propio acting mendicante, sobre todo cuando el niño padecía alguna discapacidad. ${ }^{17}$

En todas esas modalidades, los tópicos recurrentes en los discursos de la prensa, permeados por una sensible condena moral, remitían al alquiler de los niños para la práctica mendicante o su explotación directa por sus progenitores con el fin de sobrevivir a costa de ellos, eludiendo el trabajo. Según la crónica periodística, cuando en 1915 la policía de la ciudad inició una investigación sobre los antecedentes y medios de vida de numerosos mendigos, se había establecido que junto a muchos casos de legítima necesidad se encontraban "padres y madres que

\footnotetext{
${ }_{14}^{14} L P, 26 / 04 / 1907$, p. 2, 30/01/1918, p. 3, 06/03/1918, p. 4, 20/10/1918, p. 1; LVI, 13/08/1922, p. 6, 03/01/1928, p. 8; EP, 15/04/1928, p. 5.

${ }^{15}$ Situación semejante fue señalada para la prensa de Pontevedra de la segunda mitad del siglo XIX y primeros años del XX, en la cual pocos artículos atribuían la mendicidad infantil a la pobreza, la falta de trabajo, la enfermedad o muerte de los progenitores; por regla general, aquella se fijaba menos en el desamparo de los menores que en la irresponsabilidad paterna y/o la explotación por sus padres u otros mendigos (Rodríguez Martín, 2017, pp. 412, 422).

${ }^{16} L P, 07 / 08 / 1907$, p. 2. Sobre el lazarillo: $L P, 21 / 01 / 1906$, p. 2, 26/04/1907, p. 2, 02/09/1928, p. 7. ${ }_{17}$ Para Pontevedra en la segundad mitad del siglo XIX e inicios del XX, se señala que había casos en que los pequeños eran obligados a mendigar e, incluso, alquilados a otros mendigos, cuyas limosnas aumentaban cuando las criaturas exhibían una deformidad o discapacidad (Rodríguez Martín, 2017, p. 407).
} 


\section{Fernando J. Remedi}

envían a sus hijos a solicitar limosnas, cuyo producto se invierte en bebidas y orgías, viviendo en la ociosidad y rehuyendo el trabajo que se les ofreciera".18

En cualquiera de sus versiones, esos explotadores infantiles eran considerados como auténticos "empresarios de la mendicidad". ${ }^{19}$ Por esta vía, se ponía en tensión -cuando no en entredicho- la práctica mendicante de los niños como un recurso de última instancia para la supervivencia, coyuntural, de familias pobres con la explotación de dicha actividad como una forma de los padres de evitar su propio trabajo, deslegitimando el derecho a peticionar -en este caso, limosna- para subsistir. Así lo dejaba entrever un comentario de Los Principios:

Es imprescindible vigilar constantemente a los referidos empresarios de la mendicidad, pues si el ejercicio de ésta puede admitirse en algunos casos cuando responde a reales necesidades, no es posible coadyuvar a que se industrialice aquel recurso supremo reservado a quienes han caído en la más oscura indigencia. $^{20}$

En este caso, podría decirse que, en cierto sentido, se estaba recuperando la vieja, persistente y aún vigente distinción entre mendigo auténtico y falso, delineada a partir de la capacidad y la voluntad para trabajar. La condena moral y social del falso mendigo, por eludir el trabajo productivo, se reforzaba en este caso en tanto explotador de la mendicidad infantil, añadiéndose a la condición de padre y, más aún, de madre, una amplia serie de descalificaciones con expresiones como "madres perversas", "mujer sin entrañas", "padres ociosos y desnaturalizados", "ebrios consuetudinarios", entre otras, y reproches que apuntaban a su vagancia, vicios, ociosidad, etc. Incluso, llama la atención la asociación o equiparación de las madres o tutoras de esos niños dedicados a la mendicidad y la figura estereotipada de una bruja, como una mujer vieja y fea, sombría, desagradable, que desde las proximidades vigilaba atentamente la actividad de aquellos. ${ }^{21}$ Cuando se trataba de niñas mendicantes, a la figura de bruja supo añadirse ocasionalmente la de "celestina", sugiriendo que esa madre o tutora inducía a la prostitución a la pequeña limosnera. ${ }^{22}$

\section{La mendicidad infantil como problema social}

Cualquiera fuera la razón que explicara la existencia de la mendicidad infantil y sus diversas modalidades de explotación, la prensa reprochaba la falta de conciencia de

\footnotetext{
${ }^{18} L P, 04 / 04 / 1917$, p. 1.

${ }^{19} L P, 20 / 10 / 1918$, p. $1,24 / 10 / 1918$, p. $1 ; L V I, 03 / 01 / 1928$, p. 8.

${ }^{20} L P, 11 / 06 / 1918$, p. 1.

${ }^{21} L P, 08 / 02 / 1918$, p. 2; $L V I, 03 / 01 / 1928$, p. 8.

${ }^{22} L P, 30 / 01 / 1918$, p. 3.
} 


\section{Miradas sobre la mendicidad infantil en la ciudad de Córdoba en las primeras décadas del siglo XX}

padres y madres de quienes ejercían esa actividad, ya que -fuera por necesidad real o simple ociosidad- exponían a los menores a una serie de riesgos de diversa índole, algo sobre lo cual se advertía con énfasis y de modo recurrente desde sus páginas. Esas amenazas se cernían sobre los niños mendicantes y suponían una señal de alerta o peligro para la sociedad en su conjunto, a mediano y largo plazo, por las consecuencias morales y sociales indeseables y alarmantes atribuidas a la mendicidad.

En realidad, la mendicidad por las calles hacía parte de una problemática mayor como era la presencia y la circulación de los niños en el espacio público urbano, ajenos al control adulto o, en su defecto, estatal (Freidenraij, 2016, pp. 179, 182; Zapiola, 2010, p. 53; Paz Trueba, 2012, párr. 8). La práctica mendicante era sólo una manifestación más del difrute de una libertad excesiva por parte de los niños que transitaban las calles. Esa presencia y circulación, así como las actividades y las sociabilidades infantiles desplegadas al amparo de esa libertad permitida por la debilidad/ausencia del control adulto y/o estatal, daban lugar a un niño más o menos apartado de la imagen normativizada de la infancia dominante entre fines del siglo XIX e inicios del XX. Siguiendo los análisis de Zapiola $(2009,2010,2018)$-que en parte retoman aportes previos de Carli-, entre 1880 y 1920 en los sectores dirigentes se materializó una percepción dicotómica del universo de la infancia. Ella distinguía, por un lado, a los "niños" -menores sujetos a control adulto dentro de la familia, la escuela o, eventualmente, el trabajo en los sectores populares-, y por otro, a los "menores" -grupo urbano heterogéneo que tenía como denominador común el mantener pautas de comportamiento, circulación, educación, sexualidad, trabajo, sociabilidad y socialización familiar y extrafamiliar consideradas inconvenientes para su edad-. Esos modos clasificatorios eran mutuamente dependientes, contrastantes y complementarios y, por cierto, las definiciones y las políticas derivadas de ellos destinadas al universo infantil estuvieron atravesadas por tensiones y límites imprecisos y fluctuantes en el tiempo (Zapiola, 2018, p. 104). Más aún cuando la representación de "niño" de los sectores dirigentes fue más compleja, porque dentro de ella se distinguieron -en virtud de la Ley de Educación Común 1420- a los infantes que tenían las condiciones para convertirse en "alumnos" de aquellos otros que se configuraban a partir de las variables "hijo" y "trabajador", a las que eventual -pero no necesariamente- podía añadirse la de "alumno". Esto obedeció a diversos factores, algunos comúnmente señalados -limitaciones materiales del sistema educativo y de las condiciones de vida de los sectores populares-, pero también a otros derivados de las propias representaciones de los funcionarios y legisladores sobre qué niños podían convertirse en alumnos y cuáles no, ya que en ellos las posturas educativas universalistas coexistieron con otras que rechazaban la posibilidad -incluso la conveniencia- de que todos los infantes se incorporaran a las escuelas comunes. No pocos pensaban que, tratándose de niños de los sectores populares, para ellos nada resultaría más educativo que el taller o la fábrica (Zapiola, 2009, pp. 74, 87). En suma, en términos de representaciones dominantes en el período, el universo de la infancia quedó definido por la tríada 


\section{Fernando J. Remedi}

"niños/hijos/alumnos", "niños/hijos/(alumnos)/trabajadores" y "menores" (Zapiola, 2009, p. 73).

Los niños dedicados a la mendicidad quedaban privados del aprendizaje que suponía el trabajo honrado y/o la escolarización; en cambio, comenzaban desde temprano a dar sus primeros pasos en la "carrera de la mendicidad", ${ }^{23}$ a instruirse en el oficio de mendigar, ignorando o despojándose de todo viso de dignidad que pudieran haber tenido y/o, en su caso, perdiendo las nociones y el hábito de trabajo, en una sociedad en la cual éste era un valor central. A fines del período, La Voz del Interior sentenciaba:

Esos niños que desde tierna edad son preparados por sus padres para implorar la misericordia pública (...) que camino han de tomar al llegar a la edad madura, si lo primero que se ha hecho con ellos es hacerles perder la dignidad (...)?24

Iniciarse en la mendicidad en la infancia era prácticamente equivalente a hacerlo en la escuela de la vagancia, de la perversión, del vicio, de la delincuencia, según expresiones corrientes de la prensa. ${ }^{25}$ En Buenos Aires, promediando el decenio de 1870, habían aparecido los primeros discursos que asociaban linealmente la circulación de niños y jóvenes ajenos al control adulto por el espacio urbano con su ingreso en la delincuencia; para el cambio de siglo, esa asociación ocupaba un sitio destacado en las representaciones de la infancia de los dirigentes argentinos (Zapiola, 2009, p. 83). Según el parecer de la prensa -no sólo cordobesa-, los pequeños mendigos quedaban expuestos a ejemplos y situaciones considerados inmorales según los cánones dominantes en la época y a relaciones, contactos y espacios de sociabilidad ponderados como riesgosos. ${ }^{26}$ El niño transitaba un camino de decadencia que lo conducía de forma directa hacia el mundo del delito; ya en la calle, otros adultos y menores de mala vida lo contagiaban con sus ejemplos y la caída en prisión terminaba por corromperlo (Zapiola, 2010, p. 60) Una buena síntesis de esas concepciones sobre la mendicidad infantil la ofrece Los Principios:

\footnotetext{
${ }^{23} L P, 06 / 06 / 1909$, p. 2.

${ }^{24} L V I, 15 / 03 / 1929$, p. 16.

${ }^{25} L P, 21 / 01 / 1906$, p. $2,06 / 06 / 1909$, p. $2,30 / 01 / 1918$, p. 3, 26/03/1918, p. $1,12 / 06 / 1918$, p. 1 ; EP, $15 / 04 / 1928$, p. 5; LVI, 15/03/1929, p. 16. Discursos del mismo tenor estaban presentes en la prensa sevillana y pontevedresa, en la segunda mitad del siglo XIX e inicios del XX, que consideraban la mendicidad como el primer paso hacia la delincuencia y a los/as niños/as que la ejercían se les vaticinaba un futuro en el presidio o la prostitución (Rodríguez Martín, 2017, pp. 407, 413, 423). Según Paz Trueba (2012), la relación entre mendicidad, vagancia e inmigración era casi un lugar común en los periódicos de Azul y Tandil, en el sudoeste bonaerense, existiendo una fuerte correlación entre pobreza y vagabundeo urbano (párr. 18).

${ }^{26} L P, 21 / 01 / 1906$, p. 2, $07 / 08 / 1907$, p. 2, 11/01/1917, p. $1,04 / 04 / 1917$, p. $1,11 / 06 / 1918$, p. 1 , 19/07/1918, p. 1, 22/10/1920, p. 1; EP, 14/04/1926, p. 8, 04/08/1930, p. 6; LVI, 15/03/1929, p. 16.
} 


\title{
Miradas sobre la mendicidad infantil en la ciudad de Córdoba en las primeras décadas del siglo $\mathrm{XX}$
}

El pequeño hambriento no retrocede ante dintel alguno. Por ello se ve expuesto á tener sociedad con toda clase de gente. Ve y oye lo que está vedado, aprende á maldecir y á injuriar, adquiere el hábito de odiar á los ricos y á la sociedad que ni en cuenta lo tiene. Falto de educación y de instrucción se desenvuelve en las tinieblas de una interminable noche moral. ${ }^{27}$

Para la misma época, en Buenos Aires, se concebía que se trataba de niños en peligro moral en tres niveles: un abandono que conducía a una degradación física, que inhibía su capacidad de producción futura; una apropiación ilegítima de su trabajo por sus padres; y la pérdida del niño como futuro ciudadano (Ruibal, 1993, pp. 5758). Esos niños que reemplazaban la vida en el seno de la familia por otra en la calle, moralmente abandonados, expuestos a malas compañías por la ausencia de vigilancia adulta, bordeaban peligrosamente la mala vida y debían ser objeto de especial atención de los agentes policiales (Freidenraij, 2016, p. 174). ${ }^{28}$

Los peligros de la corrupción moral y del rápido descenso por la pendiente de la degradación social se agudizaban cuando la criatura mendicante era de sexo femenino. ${ }^{29}$ La codicia, la haraganería y el descuido de sus progenitores que la colocaban en la calle para explotar su actividad mendicante, el ejercicio de esta última en las noches y madrugadas y la eventual compañía o proximidad de otros menores que transitaban los mismos espacios convergían para poner en riesgo la moralidad de algunas niñas pobres. El testimonio más contundente de esta mirada es un suelto, suscripto con el seudónimo de "Espinita”, donde se señalaba:

\begin{abstract}
Un padre por más pervertido que sea, no puede dejar abandonada al vicio a una hija, porque, ¿qué otra cosa puede llegar a ser una criatura que vive vagabundeando todo el día, sin otra compañía que vendedores de diarios y expuesta a los mil peligros del arroyo? (...) debían evitar que esas pobres chicas, que resbalen por la pendiente de ese vicio al cual ahora son candidatas. (...) esas mujercitas (...) pierden su inocencia por el pedazo de pan. ${ }^{30}$
\end{abstract}

Con independencia del sexo de quien mendigaba, como consecuencia del contexto de amenazas que pendían sobre él o ella, la prensa emitía constantes señales de

\footnotetext{
${ }^{27} L P, 26 / 04 / 1907$, p. 2.

${ }^{28}$ Lo mismo subraya Paz Trueba (2012) para Azul y Tandil, cuando alude a esos niños en la calle que estaban en peligro de perderse por la convivencia con personas y espacios inapropiados para su edad (párr. 18).

${ }^{29}$ La prensa de Córdoba en muy pocas ocasiones distingue a las niñas dentro del colectivo de niños mendicantes. Algo parecido fue observado por Paz Trueba (2012) para Tandil y Azul, quien afirma que en sólo una oportunidad la prensa mencionó la mendicidad ejercida por niñas. Según la autora, las fuentes utilizadas por ella -prensa, documentación policial y de la defensoría de menores- dan menos visibilidad a la vulnerabilidad de las niñas respecto de los niños por la naturaleza del trabajo realizado por cada uno de esos segmentos de la infancia popular -en el ámbito doméstico y el espacio púbico, respectivamente-; no obstante, todo ese colectivo compartía una significativa vulnerabilidad en términos de exposición al abandono, el vagabundeo o la miseria (párr. 40, 44-45).

${ }^{30}$ Espinita. Mendicidad infantil. $L P, 28 / 01 / 1917$, p. 3.
} 


\section{Fernando J. Remedi}

alarma por los peligros que acecharían a la sociedad en un futuro no lejano. Ese niño en peligro moral corría el riesgo de devenir con el tiempo en un niño peligroso para la sociedad (Ruibal, 1993, p. 57). En virtud de la constante exposición a "los peligros de la calle", había un consenso extendido en el sentido de que esas criaturas devendrían, fatalmente, vagas, viciosas y, casi inevitablemente, delincuentes, "carne de presidio", convirtiéndose en un problema social. ${ }^{31}$ Encarnaban a parte de los "futuros clientes de las cárceles y los lupanares",32 niños y niñas, respectivamente. Según Freidenraij (2016) para la Buenos Aires de la época, toda una serie de prácticas infantiles fueron objeto de una intervención policial cada vez mayor entre 1885 y 1920, que buscaba ordenar la presencia infantil en el espacio urbano y, en particular, controlar las moralidades de ese segmento de la población. Ello obedeció a la asociación cada vez más firme entre toda una serie de prácticas infantiles en el espacio público, el bajo fondo social y su calificación como actitudes "predelictuales", es decir, premonitorias del delito, anticipatorias de conductas reprensibles desde el punto de vista moral y legal, potenciales atentados contra el orden social (pp. 170, 190, 193). Como destaca Zapiola (2010) sobre la criminología positivista, para esta perspectiva, tratándose de menores, para decidir sobre su encierro en instituciones correccionales, poco importaba la comisión de delitos, interesaba mucho más el incumplimiento de ciertas normas de conducta que se suponía que todo niño debía respetar, con independencia de que su transgresión estuviera o no sancionada por la ley (pp. 64, 69).

A veces se iba más allá de ponderarlo como problema social, apuntándose a una dimensión más estrictamente política, porque no dejaba de atenderse al efecto nocivo que esa situación tendría para la nacionalidad y la ciudadanía si éstas se construían sobre cimientos constituidos por individuos de esa pobre naturaleza moral. Los Principios advertía seriamente sobre el calificativo de "infantil" aplicado a "mendicidad", considerando que en ese caso aquel se convertía en una "deformidad física y moral", y que al hacerse crónica esa actividad, empezaba "por trabajar hondamente el porvenir de la raza". ${ }^{33}$ En 1918, cuando se había expandido notoriamente la mendicidad infantil, el periódico la consideraba como parte de "la niñez abandonada y vagabunda", "una cuestión social y, más que todo, de nacionalidad". ${ }^{34}$ Esos pequeños varones serían, en el futuro, "los ciudadanos de la patria", sobre los cuales se fundamentaría "la prosperidad del país". ${ }^{35}$ En el otro

${ }^{31} L P, 26 / 04 / 1907$, p. 2, 07/08/1907, p. 2, 06/06/1909, p. 2, 04/04/1917, p. 1, 26/03/1918, p. 1 , $12 / 06 / 1918$, p. $1,19 / 07 / 1918$, p. $1,15 / 02 / 1919$, p. 1 ; $E P, 14 / 04 / 1926$, p. 8, 15/04/1928, p. 5, $04 / 08 / 1930$, p. 6 .

32 LP, 30/01/1918, p. 3. Paz Trueba (2012) observa idénticas apreciaciones en la prensa de Tandil y Azul, con mayor énfasis en El Imparcial de esta última, donde esos menores fueron considerados como población que colmaría cárceles, hospitales y asilos (párr. 24). Concepciones semejantes estaban vigentes en la prensa y los reformadores sociales en España hacia la segunda mitad del siglo XIX y primeros años del XX, considerando que la mendicidad determinaba el futuro de los niños; a los varones los predisponía a la delincuencia y el presidio y a las niñas a la prostitución, además de provocarles un fuerte resentimiento social (Rodríguez Martín, 2017, pp. 407, 423).

${ }^{33} L P, 26 / 04 / 1907$, p. 2.

${ }^{34} L P, 19 / 07 / 1918$, p. 1.

${ }^{35} L P, 15 / 02 / 1919$, p. 1. 


\section{Miradas sobre la mendicidad infantil en la ciudad de Córdoba en las primeras décadas del siglo XX}

extremo, en el mejor de los casos, en coincidencia con la mirada de la prensa sobre la mendicidad adulta (Remedi, 2017, pp. 513-514), ${ }^{36}$ los niños dedicados a ella acabarían siendo inútiles para la sociedad,37 una "rémora para el progreso",38 parásitos del conjunto social, al cual no aportarían el concurso de sus energías y trabajo productivo. Esta cuestión no era menor en el contexto de un país en tránsito de modernización, que experimentaba una expansión económica sostenida; en la mirada de los elencos dirigentes -no sólo políticos y estatales- los niños representaban los futuros trabajadores que permitirían consolidar un proyecto de país próspero, moderno y civilizado.

\section{¿Qué hacer frente a la mendicidad infantil?}

Si había un consenso bastante generalizado sobre los perjuicios individuales y sociales derivados de la mendicidad infantil, así como sobre sus consecuencias en el futuro de la sociedad, en cambio, existían algunos matices respecto a cómo actuar frente a ese problema social.

Había unanimidad en que la falsa mendicidad y la explotación infantil en esa actividad debían reprimirse con miras a su supresión. Pero cuando la mendicidad era el último recurso de los pobres, por las desfavorables coyunturas -especialmente por la falta de oportunidades laborales- o como consecuencia de circunstancias personales -etarias, físicas, psíquicas- que imposibilitaban para el trabajo, las posiciones que se visualizan en la prensa eran más matizadas y flexibles. En el segundo caso, sobre todo el período sobrevuela la concepción de que los impedidos de trabajar de manera permanente debían ser recogidos en establecimientos de asistencia social, a cargo del Estado, la beneficencia o la filantropía.

La vigencia de circunstancias económicas muy desfavorables incluso daba lugar, a veces, a cierta legitimación, aunque tímida e implícita, de la mendicidad infantil. Es muy iluminador el editorial "Un problema social”, publicado por Los Principios en junio de 1918. En él, cuando se alude a la represión de la mendicidad infantil, se hace la salvedad de que esa acción debía recaer sobre su ejercicio "indebido", para luego intentar persuadir a la policía para que no persiguiera a los niños mendigos, atendiendo a las circunstancias económicas reinantes. Contemplando que esa actividad en esos momentos era un recurso obligado para muchas familias pobres,

\footnotetext{
36 Del mismo modo, en la ciudad de México a fines del XIX, la retórica del discurso que sostuvo un tratamiento asistencial diferenciado para los mendigos respecto de otros grupos de pobres fue la construcción de una categoría cuya característica central era que no realizaba contribuciones útiles a la sociedad, aunque sin transgredir una ética del trabajo (Lorenzo, 2015, p. 347). A su vez, la prensa de Sevilla en el viraje del siglo XIX al XX presentaba al mendigo, en tanto que no trabajaba, como un inútil para sí mismo e improductivo para la sociedad; en la ociosidad estaba uno de los argumentos más decisivos de la crítica moral hacia el mendigo y en la configuración de su imagen como antisocial (Velasco Mesa, 1995, p. 250).

${ }^{37} L P, 06 / 06 / 1909$, p. 2; $E P, 14 / 04 / 1926$, p. 8.

${ }^{38} L P, 15 / 02 / 1919$, p. 1.
} 


\title{
Fernando J. Remedi
}

se sostenía que una campaña decidida en contra de ella no sólo sería cruel sino también ineficaz para conjurar un problema que excedía la aptitud y la voluntad de los individuos para el trabajo. Tras aludir a los "caracteres inmensamente dolorosos" que asumía "el espectáculo de la mendicidad infantil" y "el extraordinario número de niños indigentes que ambulan por algunas calles a horas avanzadas de la noche, implorando las limosnas", el periódico católico recomendaba:

\begin{abstract}
No creemos que deba emplearse medidas de rigor, como se ha hecho algunas veces, con los pobres niños que obligados por la miseria acuden a los sentimientos caritativos del pueblo. Esas medidas constituirían una verdadera crueldad y no solucionarían, por otra parte, el difícil problema. (...) frente a situaciones de tal carácter, no cumple adoptar medidas represivas, tan injustificadas como ineficaces. ${ }^{\prime \prime 39}$
\end{abstract}

En otros casos, aunque sin ignorar la desfavorable coyuntura, pero subestimando su incidencia sobre la mendicidad infantil, atribuyendo prácticamente toda la responsabilidad de la misma a la "codicia y haraganería de sus padres o parientes", una contemporánea reclamaba por una disposición municipal que prohibiera dicha actividad, ${ }^{40}$ especialmente la del sexo femenino, por el riesgo de corrupción moral. ${ }^{41}$ En general, entre las opiniones vertidas en la prensa había gran coincidencia en la necesidad de brindar protección social a los niños mendicantes, de diversos modos: poniéndoles a resguardo de los "peligros de la calle"; ofreciéndoles un mínimo de bienestar material y cultural, en este caso por el acceso a la educación elemental y/o en el aprendizaje de un oficio; y liberándolos de la explotación de la que se suponía que, por lo común, eran víctimas a manos de sus padres, madres o tutores. ${ }^{42}$

Era urgente actuar sobre esa realidad intentando redimir a los niños mendicantes para luego regenerarlos, cuando resultaran aptos para una iniciativa de esta naturaleza. En ese sentido, con cierta frecuencia en la prensa se recurría a expresiones como "elementales deberes de higiene social", "labor de saneamiento ineludible",43 "punto de higiene social",44 "purificación social", 45 en alusión a la necesidad de intervenir, especialmente desde el Estado -a menudo, específicamente

\footnotetext{
${ }^{39} L P, 11 / 06 / 1918$, p. 1.

40 Para Pontevedra en la segunda mitad del XIX, la opinión generalizada de la prensa y los reformadores sociales era que la mendicidad infantil debía prohibirse, porque favorecía la explotación de los niños y su corrupción. La ley de 1903 que prohibía limosnear a los menores de 16 años no fue observada, según denunciaban periódicos y especialistas (Rodríguez Martín, 2017, pp. 422-423).

41 Llama la atención que en la misma nota en algún momento se suaviza el tono de la demanda a los poderes comunales, solicitando que la prohibición alcanzara al menos a la mendicidad infantil por las noches y primeras horas del día. Espinita. Mendicidad infantil. $L P, 28 / 01 / 1917$, p. 3.

$42 L P, 08 / 11 / 1917$, p. 1 ; $E P, 04 / 08 / 1930$, p. 6.

43 LP, 11/06/1918, p. 1.

${ }^{44} L P, 04 / 04 / 1917$, p. 1.

${ }^{45} L P, 30 / 01 / 1918$, p. 3.
} 


\section{Miradas sobre la mendicidad infantil en la ciudad de Córdoba en las primeras décadas del siglo $\mathrm{XX}$}

desde la policía- sobre la mendicidad infantil. ${ }^{46}$ Es aplicable aquí lo expresado por Velasco Mesa (1995) para Sevilla en el viraje el siglo XIX al XX, cuando sostiene que en la prensa de esos años la distancia entre el discurso médico o higienista y el moral es, en muchas ocasiones, imperceptible; esas lecturas se intercalan y, con frecuencia, son consustanciales y difícilmente distinguibles (p. 249). A la vez, comenzó a plantearse con alguna frecuencia que lo más conveniente era la prevención social, evitando que los niños devinieran mendicantes. ${ }^{47}$

Regeneración o prevención, la prensa y los contemporáneos que difundían sus ideas a través de ella coincidían en atribuir ambas tareas, simultáneamente, al Estado y a agencias de la sociedad civil -entidades benéficas y filantrópicas-. Así, para la cuestión específica de la mendicidad infantil se apelaba al modelo mixto benéficoasistencial de atención de lo social, aún dominante en la Córdoba de entonces, para mitigar los desajustes sociales que habían acompañado al crecimiento y la modernización del último tercio del siglo XIX y el primero del XX (Moreyra, 2009, p. 373). Al Estado -de manera directa y, además, financiando a esos actores de la sociedad civil- y a estos últimos les correspondía operar sobre la mendicidad infantil mediante la puesta en marcha de nuevos asilos y la manutención y ampliación de los existentes, porque la opinión generalizada era que las prestaciones disponibles resultaban insuficientes frente a la magnitud alcanzada por ese problema social. ${ }^{48}$ Para fines del período, se estimaba que el Estado -al que le cabía la responsabilidad principal sobre la mendicidad infantil- aún no contaba con los dispositivos institucionales adecuados para enfrentar ese problema social. El periódico conservador El País sostenía en 1928 que el Estado carecía de los "institutos modernos indispensables para retener y reeducar a este pequeño tipo de vagabundo", le faltaban los medios necesarios en términos de locales y personal apto para dichas responsabilidades. ${ }^{49}$

Esa deficiencia llevaba incluso a que se pusiera en tela de juicio la conveniencia de que la defensoría de menores interviniera en la protección de esos infantes abandonados -o supuestamente tales- que, muy a menudo, se dedicaban a limosnear. Cuando en 1928 un defensor de menores solicitó a la jefatura de policía que recogiera a los niños abandonados que hallara en las calles, El País objetó con vehemencia la iniciativa, porque la insuficiencia de la oferta estatal de locales y personal idóneo para asilar convenientemente a esos niños supondría, en la práctica, que terminarían mezclándose en la comisaría "con toda clase de maleantes y personas de mal vivir" o, en el mejor de los casos, remitiéndolos a un asilo que

\footnotetext{
46 Ella era sólo una manifestación concreta de una cuestión mayor, la presencia y las formas de circulación de niños y jóvenes en el espacio público urbano, que durante el período fue objeto de particular atención de la policía en la Buenos Aires de 1885-1920. En ese lapso, la policía produjo y aplicó una detallado corpus de normas y sanciones que convirtió en infracciones prácticas hasta entonces habituales y permitidas; el objetivo básico era ordenar la presencia infantil en el espacio urbano (Freidenraij, 2016).

${ }^{47} L P, 11 / 06 / 1918$, p. $1,19 / 07 / 1918$, p. 1.

${ }^{48} L P, 08 / 11 / 1917$, p. $1,12 / 06 / 1918$, p. $1 ; E P, 28 / 07 / 1928$, p. 4, 04/08/1930, p. 6.

${ }^{49} E P, 28 / 07 / 1928$, p. 4.
} 


\section{Fernando J. Remedi}

carecía de las condiciones adecuadas, de modo que -en cualquiera de las alternativas- los infantes serían perjudicados. ${ }^{50}$ En cambio, sostenía que muchos de esos niños, aunque se vieran "andrajosos, sucios y sin lavar", dando "la impresión del abandono absoluto", tenían un hogar, y que "la inmensa mayoría" realizaba en las calles "algún pequeño trabajo", de modo que estaba "protegido por la mirada del público" y, por trabajar, estaba "recibiendo, de continuo, en forma algo inconsciente pero eficaz, una lección mucho más provechosa de la que puede recojer [sic] en centros que hoy todavía no se hallan debidamente organizados."51

De todos modos, esa situación parece haber sido percibida como un mal menor, ya que el mismo periódico, dos años más tarde, frente al mismo problema de la infancia abandonada y mendicante sostenía que de existir leyes que impidieran el trabajo callejero a los niños, "las cárceles se verían menos pobladas y en cambio habría más hombres de bien sobre la tierra". ${ }^{52}$ Como ya se señaló, según las concepciones vigentes, el niño en peligro solía devenir en niño peligroso para la sociedad, por las tendencias criminógenas de la criatura -producto del innatismo de caracteres mórbidos o su heredabilidad- y, mucho más, de las influencias del medio social, que el discurso positivista de la época consideraba determinantes en el desarrollo de la criminalidad infantil (Ruibal, 1993, pp. 56-59). Según la criminología positivista, el delito infantil reconocía tanto la herencia como las influencias del medio, siendo común que los individuos que transgredían la ley -o presuntamente lo haríanestaban sometidos a "un cúmulo complejo de influencias hereditarias y mesológicas, que en cada caso habían impedido la 'normal' inhibición de las tendencias antisociales"; estas últimas, naturales en el hombre, luego eran reducidas a un estado latente por la formación de centros inhibitorios o del sentido moral a través de la educación (Zapiola, 2010, pp. 57-59). Así, un principio rector del pensamiento positivista sobre la infancia y la minoridad era la confianza depositada en la educación como instrumento para la regeneración de los niños y jóvenes (Zapiola, 2010, p. 59).

El niño mendigo y el que trabajaba en la calle compartían a ésta como escenario cotidiano de parte de sus actividades, por tanto quedaban también expuestos a los peligros y riesgos atribuidos a ese espacio, además de transitar sus vidas dentro del mundo de los pobres. Más allá de ello, la prensa suele presentar a ambos niños en la calle como realidades diferentes, distantes, por sus respectivas actividades, rescatando además -aunque tímidamente y de modo ocasional- ciertos rasgos

\footnotetext{
${ }^{50}$ En los albores del siglo XX estaba instalada la idea del asilo de reforma como institución concebida para aislar físicamente a los menores encausados y condenados de la corruptora compañía de los adultos delincuentes con los que compartían el encierro en dependencias policiales u otros ámbitos carcelarios, a la vez que para brindarles una oportunidad de regeneración mediante la educación en el trabajo y la disciplina (Zapiola, 2010, p. 63). Sobre esas bases se creó en Buenos Aires en 1898 el Asilo de Reforma de Menores Varones. Sin embargo, hacia mediados de la década de 1910 comenzaron a formularse otras alternativas para tratar a esos menores, las cuales por lo general supusieron "una vigorosa recusación de la institución de menores tal como había sido imaginada" (Zapiola, 2010, p. 63).

${ }^{51} E P, 28 / 07 / 1928$, p. 4.

${ }^{52} E P, 04 / 08 / 1930$, p. 6.
} 


\section{Miradas sobre la mendicidad infantil en la ciudad de Córdoba en las primeras décadas del siglo $\mathrm{XX}$}

positivos vinculados al niño trabajador, por su inicio y aprendizaje en el mundo laboral.

Si bien eso no era lo deseable o ideal para un niño, aparecía como la opción menos mala frente a la mendicidad. En todo caso, uno de esos niños se estaba educando en el valor fundamental del trabajo, mientras que el otro se acostumbraba a vivir del esfuerzo ajeno, perdiendo con el tiempo todo prurito por esa situación. Los Principios condenaba a los explotadores de los niños, pero casi imperceptiblemente distinguía entre los recursos provenientes del trabajo y los de la mendicidad infantiles: "En el producido de sus manos que se alargan para pedir, no para trabajar, encuentran el sustento una ó más personas miserables, holgazanas ó viciosas". ${ }^{53}$ En el mismo sentido, y con semejante tenor crítico, años después volvía sobre la distinción entre trabajo y mendicidad infantiles, condenando moralmente a esta última como algo desvergonzado:

Hay muchos padres que no ven en sus hijos otra cosa que instrumentos para adquirir lo necesario para su vida, pero no encaminándolos por la senda del trabajo sinó [sic] iniciándolos en la desvergüenza de solicitar un mendrugo de pan en cada puerta. ${ }^{54}$

Sin embargo, para la misma prensa, que se esforzaba por presentar esas realidades como diferentes, la frontera entre ambas no parece haber sido tan nítida, sino más bien difusa y permeable, a consecuencia de algunas de las amenazas de la calle que se cernían sobre los niños. Así, solía presentarse la situación de que los niños que habían terminado su trabajo recurrían luego a la mendicidad como alternativa para allegarse unas monedas adicionales para destinarlas a juegos callejeros por dinero, ya agotados los recursos provenientes de su actividad. ${ }^{55}$ Más en general, como sostiene Zapiola (2009) en alusión a Buenos Aires en el inicio del siglo XX, en el "sentido común de los contemporáneos" se había instalado la idea de un "vínculo necesario entre el trabajo en las calles y la delincuencia precoz" (p. 84). ${ }^{56}$

\footnotetext{
$53 L P, 26 / 04 / 1907$, p. 2. Destacado del autor.

${ }^{54} L P, 19 / 07 / 1918$, p. 1. Destacado del autor.

55 EP, 04/08/1930, p. 6. Para la policía de la ciudad de Buenos Aires, los juegos por dinero eran una "ociosidad peligrosa" ubicada en el corazón de la argumentación institucional que hallaba en ella "la clave de la degeneración moral que, más temprano que tarde, acabaría con el mocoso en la cárcel”; el juego, "arena de corrupción moral", era un vicio que crecía paralelamente al desarrollo del niño, donde se diluían los valores burgueses del ahorro y el trabajo honesto y se materializaban la codicia, la búsqueda de dinero fácil y los ardides para conseguirlo (Freidenraij, 2016, pp. 187-189).

56 La figura del niño trabajador en esa ciudad había comenzado a delinearse a inicios de la década de 1880 con un perfil bifronte: el niño que trabajaba en el taller o la fábrica debía ser protegido física y moralmente por el gobierno, mientras que el que lo hacía en la calle estaba en peligro moral y devenía peligroso, requiriendo un tratamiento específico (Zapiola, 2009, p. 84).
} 


\section{Fernando J. Remedi}

\section{Reflexiones finales}

Este trabajo es un primer acercamiento a la mendicidad infantil en Córdoba en las décadas de 1910 y 1920, examinando las miradas vehiculizadas por la prensa sobre ella y las concepciones subyacentes. En torno a los inicios de aquel decenio comenzó a emerger la mendicidad infantil como cuestión que despertó fuerte interés de la prensa y rápidamente, en el transcurso de la Gran Guerra, adquirió entidad e identidad propia frente a la mendicidad en general. Como se señaló, en parte eso obedeció a un proceso mayor que, desde fines del siglo XIX, supuso una creciente diferenciación entre el universo infantil y el adulto, definiéndose qué se consideraba apropiado o inconveniente para cada uno de ellos; como parte de ello, se promovió un corrimiento de la presencia y la circulación de los niños de los espacios públicos. En esa distinción entre mendicidad infantil y adulta también influyó mucho la creciente visibilización del contingente de niños que se volcaron a las calles para limosnear como parte de las estrategias de supervivencia de los pobres en una coyuntura económica muy desfavorable. Por esto último, en ese período en la prensa comenzaron a emerger miradas más matizadas y complejas acerca de la mendicidad que las tradicionales, aún vigentes, que enfatizaban sólo en las razones personales y morales de ese fenómeno, atribuyéndolo a una responsabilidad individual. Las aciagas circunstancias económicas que coincidieron con la guerra impulsaron un reconocimiento creciente, aunque aún tímido y coyuntural, de una causalidad social de la mendicidad y, por tanto, de una responsabilidad colectiva frente a ella.

Aun así, esas razones contextuales quedaron algo desdibujadas frente al énfasis colocado sobre otras causas por la prensa y los contemporáneos, que terminaban remitiendo a la responsabilidad de los mismos pobres por la mendicidad infantil: la instrumentalización que padres o tutores hacían de los niños. Fuertes y numerosas críticas, de marcado tono moralizante, arreciaron contra los explotadores infantiles $\mathrm{y}$, de un modo u otro, terminaban responsabilizando a los pobres por su pobreza, señalando que tenían una extensa prole, vivían en la holganza, consumían alcohol en exceso, rehuían al trabajo, entre otras cuestiones. En suma, la práctica mendicante de los niños terminaba atribuyéndose a la falta de conciencia y responsabilidad de los progenitores o tutores, sólo ocasionalmente a la pobreza o las circunstancias vitales desfavorables, nunca a las estructuras socioeconómicas. En el mismo sentido, las voces de y en la prensa reprochaban con insistencia la actitud poco responsable de adultos que exponían a las criaturas a los peligros de la calle, tomando cuerpo la figura del niño en peligro moral. Los pequeños mendigos vivían bajo la amenaza de un rápido descenso moral, privados del aprendizaje de un oficio y de la escuela, adquiriendo fácilmente el reprobable hábito de vivir del esfuerzo ajeno. El deslizamiento por la pendiente de la degradación moral conduciría al niño en peligro, casi inexorablemente, a convertirse en niño peligroso para la sociedad, además acicateado por un hondo resentimiento social.

Frente a la mendicidad infantil, constituida en problema social, las visiones de la prensa sobre las posibles soluciones exhibían ciertos matices. En principio, había una aceptación bastante generalizada de la idea de reprimir la mendicidad y su 


\section{Miradas sobre la mendicidad infantil en la ciudad de Córdoba en las primeras décadas del siglo XX}

explotación por terceros, por la instrumentalización de las criaturas y las consecuencias perjudiciales que tenía su ejercicio por parte de niños para ellos y el tejido social. No obstante, cuando la criatura contribuía al sostén familiar, había cierta legitimación social de su práctica mendicante, tímida, quizás momentánea por la crisis económica-, por lo común más implícita que explícita.

En cualquier caso, existía una coincidencia generalizada en la demanda de una protección social de los niños mendicantes, extendida y que abarcaba varios frentes. En ese marco, era necesario regenerar a quienes habían comenzado a transitar el camino de la degradación moral y prevenir la caída de los demás, enfatizándose más en esto último con el avance del período.

La prensa y los particulares que se expresaban en sus páginas sostenían la conveniencia y, más aún, la necesidad de que las respuestas al problema de la mendicidad infantil provinieran de un esfuerzo conjunto en el cual convergieran armónicamente- las iniciativas del Estado y de la sociedad civil organizada. Pero a medida que avanza el período se percibe un fortalecimiento de la demanda dirigida hacia el Estado para que tomara un rol más protagónico para conjurar la mendicidad infantil, multiplicando, ampliando y diversificando los asilos e incrementando su personal. Aun a fines del período se reconocía, de manera generalizada, que esa oferta estatal exhibía severas deficiencias, lo cual sembraba dudas sobre qué hacer, realmente, con las criaturas mendicantes. En esto último influyeron las aludidas limitaciones materiales, pero a ellas muy probablemente se añadieron consideraciones de otra índole, del plano de las concepciones e ideas, que se expresaron en voces críticas que discrepaban sobre las bondades atribuidas a las instituciones que pretendían regenerar a los menores, las cuales se fortalecieron e hicieron más explícitas en la segunda mitad de los años 1910 (Zapiola, 2010, pp. 6768).

Con el progreso del período, se percibe que al problema de la mendicidad infantil le subyacía una cuestión de mayor envergadura, más preocupante socialmente, como era la niñez en situación de abandono material y, sobre todo, moral. Para fines de los años 1920, la mendicidad infantil en Córdoba parece ser un fragmento de una problemática más profunda y acuciante como era la niñez material y/o moralmente abandonada, figura plasmada legalmente en 1919, en virtud de la sanción de la ley nacional de Patronato de Menores, que definió ese estatus jurídico y delineó un tratamiento específico para aquellos a quienes se aplicara.

Las miradas y las concepciones sobre la mendicidad y los mendigos, en particular los diagnósticos acerca de sus razones, orientaban la formulación de propuestas para conjurar ese problema social que acompañaba -sin desearlo- a la expansión económica, demográfica y urbana y la modernización. Así, este trabajo es un modesto avance sobre qué se concibió que debía hacerse frente a la mendicidad y, más aún, qué es lo que realmente se hizo al respecto en la Córdoba de entre siglos. 


\section{Fernando J. Remedi}

\section{Fuentes}

El País, Córdoba, Años 1926-30.

La Voz del Interior, Córdoba, Años 1910-14, 1916-30.

Los Principios, Córdoba, Años 1894-1925, 1927-30.

\section{Bibliografía}

Aversa, M.M. (2003). Vagos, mendigos y delincuentes: La construcción social de la infancia peligrosa. Buenos Aires, 1900-1910. Cuadernos del Sur. Historia, 32, 9-26.

Carasa Soto, P. (1992). La historia y los pobres: de las bienaventuranzas a la marginación. Historia Social, 13, 77-99.

Freidenraij, C. (2016). Intervenciones policiales sobre la infancia urbana. Ciudad de Buenos Aires, 1885-1920. Revista Historia y Justicia, 6, 164-197. doi: 10.4000/rhj.5

Lorenzo, M.D. (2018). El análisis de la pobreza y la campaña contra la mendicidad en la ciudad de México, 1929-1931. Historia Mexicana, LXVII (4), 1677-1724.

Lorenzo Río, M.D. (2015). Los mendigos en la ciudad de México. Perfiles de la pobreza urbana a finales del siglo XIX. En J. M. Cerdá et al. (Coords.). El auxilio en las ciudades. Instituciones, actores y modelos de protección social. Argentina y México. Siglos XIX y XX (pp. 341-365). Córdoba, CEH “Prof. Carlos S. A. Segreti”, El Colegio Mexiquense.

Moreno, J.L. (2012). Un asilo para los pobres. Los mendigos y sus historias de vida (Buenos Aires a mediados del siglo XIX). Rosario: Prohistoria.

Moreyra, B. (2009). Cuestión social y políticas sociales en la Argentina. La modernidad periférica. Córdoba, 1900-1930. Bernal: Universidad Nacional de Quilmes.

Paz Trueba, Y. (2012). Niños y niñas en el espacio urbano. La provincia de Buenos Aires entre fines del siglo XIX y principios del XX. Nuevo Mundo Mundos Nuevos, Débats, doi: 10.400/nuevomundo.63211

Paz Trueba, Y. (2015). ¿Qué hacer con los niños pobres? Vagabundeo, abandono y circulación de menores en la campaña centro y sur bonaerense. Fines del siglo XIX y primeras décadas del XX. En J. M. Cerdá et al. (Coords.). El auxilio en las ciudades. 


\section{Miradas sobre la mendicidad infantil en la ciudad de Córdoba en las primeras décadas del siglo XX}

Instituciones, actores y modelos de protección social. Argentina y México. Siglos XIX y XX (pp. 321-340). Córdoba: CEH “Prof. Carlos S. A. Segreti”, El Colegio Mexiquense.

Paz Trueba, Y. (2018). Discursos y prácticas políticas hacia la infancia en la provincia de Buenos Aires. Niñas y niños a principios del siglo XX. Revista de Indias, LXXVIII (272), 237-261.

Remedi, F.J. (2003). La sociedad en la guerra. Alimentación y Primera Guerra Mundial en Córdoba (Argentina). Prohistoria, 7, 153-176.

Remedi, F.J. (2011). Los grupos sociales en la modernización latinoamericana de entre siglos. Actores, escenarios y representaciones (Argentina, Chile y México, ss. XIX-XX). En F. J. Remedi, T. Rodríguez Morales (Eds.). Los grupos sociales en la modernización latinoamericana de entre siglos. Actores, escenarios y representaciones (Argentina, Chile y México, ss. XIX-XX)(pp. 9-20). Córdoba: CEH "Prof. Carlos S. A. Segreti", Santiago: Centro de Estudios Culturales Latinoamericanos.

Remedi, F.J. (2017). «Pululan por nuestras calles infinidad de menesterosos». Miradas y concepciones sobre la mendicidad. Córdoba (Argentina), en el tránsito del siglo XIX al XX. Historia 396, 7 (2), 507-535.

Rheinheimer, M. (2009). Pobres, mendigos y vagabundos. La supervivencia en la necesidad, 1450-1850. Madrid: Siglo XXI de España.

Rodríguez Martín, A. M. (2017). La visión de la mendicidad en la prensa de Pontevedra (1850-1903). Cuadernos de Estudios Gallegos, LXIV (130), 399-429, doi: 10.3989/ceg.2017.130.11

Ruibal, B. (1993). Ideología del control social. Buenos Aires 1880-1920. Buenos Aires: CEAL.

Velasco Mesa, C. (1995). La mendicidad en el discurso de la prensa sevillana, 18981900: de «problema social» a «amenaza de la multitud miserable». Revista de Historia Contemporánea, 6, 241-264. Recuperado de http://institucional.us.es/revistas/contemporanea/6/art 11.pdf

Woolf, S. (1990). Estamento, clase y pobreza humana. Historia Social, 8, 89-100.

Zapiola, M.C. (2009). Los límites de la obligatoriedad escolar en Buenos Aires, 18841915. Cadernos de Pesquisa, 39 (136), 69-81. Recuperado de http://publicacoes.fcc.org.br/ojs/index.php/cp/article/view/275/286. 


\section{Fernando J. Remedi}

Zapiola, M.C. (2010). Espacio urbano, delito y "minoridad": aproximaciones positivistas en el Buenos Aires de comienzos del siglo XX. Revista Educación y Pedagogía, 22 (57), pp. 51-72. Recuperado de https://issuu.com/revistaeyp/docs/isuu

Zapiola, M.C. (2018). Estado e infancia en Argentina: Reflexiones sobre un recorrido historiográfico. En L. Lionetti (Comp.). La historia de las infancias en América Latina (pp. 91-110). Tandil: Universidad Nacional del Centro de la Provincia de Buenos Aires

Recibido: $12 / 08 / 2019$

Evaluado: $11 / 09 / 2019$

Versión Final: 20/11/2019 